DOI: http://dx.doi.org/10.4314/star.v4i2.39 ISSN: 2226-7522(Print) and 2305-3372 (Online) Science, Technology and Arts Research Journal Sci. Technol. Arts Res. J., April-June 2015, 4(2): 278-287 Journal Homepage: http://www.starjournal.org/

Original Research

\title{
A Study on the Practices of Cooperative Language Learning Method: Enango High School Grade 9 in Focus
}

\author{
Zeleke Teshome Lucha* and Tsega Megersa Bongase
}

Institute of Language Studies and Journalism, Department of Language Studies and Literature, Wollega University, Post Box No: 395, Nekemte, Ethiopia

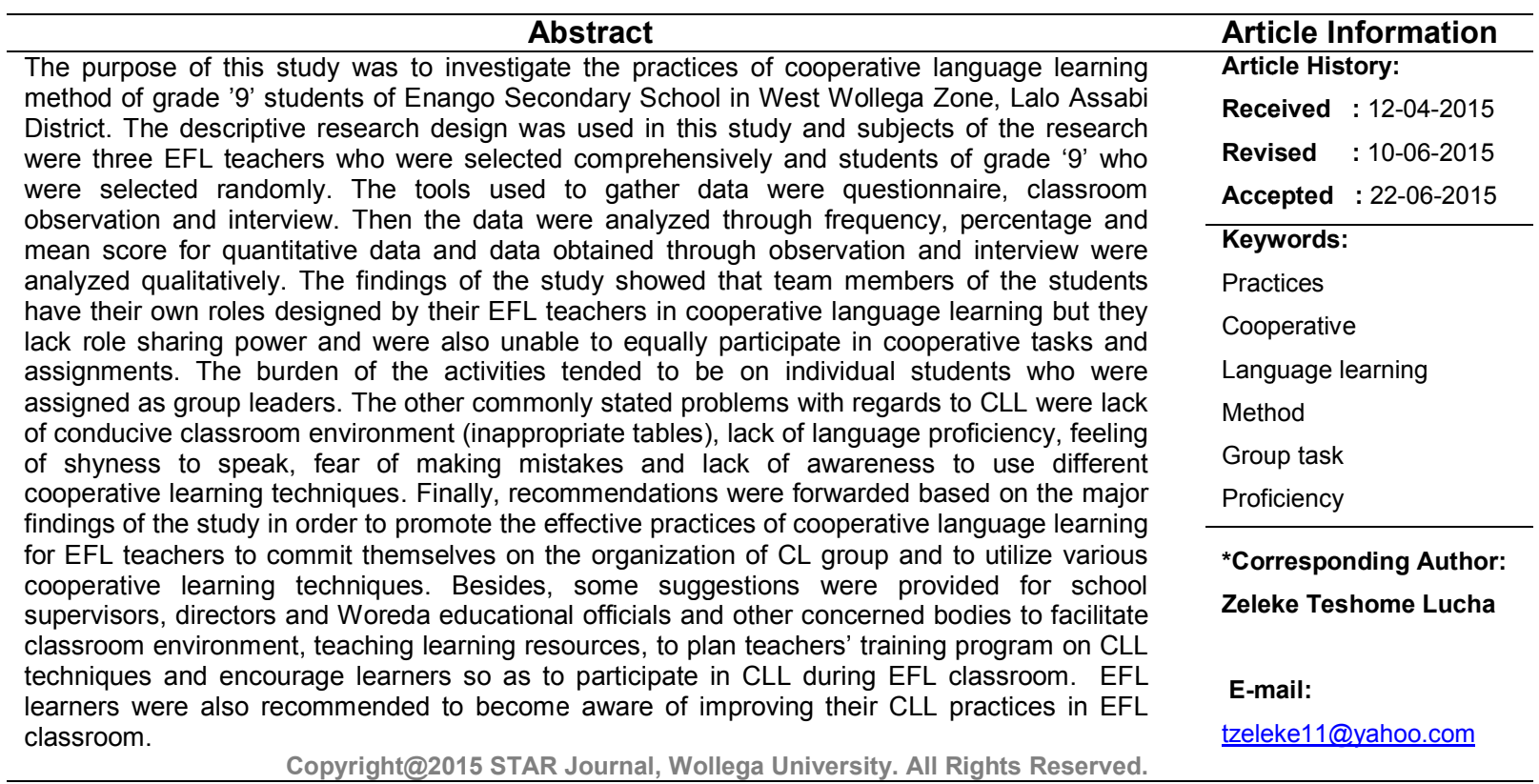

\section{INTRODUCTION}

Cooperative language learning method is widely accepted method in EFL classroom. Now a day, the new method that our country is practicing is student-centered approach which needs active participation of learners, meaningful interaction among students and solving problems cooperatively for mutual benefit. Therefore, this paper aims to investigate the practices of cooperative language learning of grade 9 students during EFL classroom at Enango Secondary School.

The theory of foreign language teaching and learning has come through very long history. The earliest method of language teaching is 'grammar translation method' which was used in teaching classical language i.e. Latin and Greek in US schools and colleges. Kelly (cited in Richards and Rodgers, 1998) states about three different theoretical views of language teaching. The first and the most traditional one is the structural view of language teaching which considered language as a system of structurally related elements its target is only for the mastery of elements of language. The second is the functional view which focuses on language as the vehicle for the expression of functional meaning. This view of language teaching is in which the movement of communicative language teaching is begun to be subscribed. The latest view of language teaching is the interactional view, which emphasized on language as a vehicle for the realization of interpersonal relations and performance of social transaction between individuals.

Similarly, Brown (2000) puts forward the theory that corresponds to CLL is social constructivist theory which is associated with more current approaches to second language acquisition and emphasizes the dynamic nature of the interplay between learners and their peers, their teachers and others with whom they interact. This theory confirms the interaction among learners and develops team spirits with ample access to cooperation. It holds the principle that learning involves active process and engagement of students with peers and other social groups. Other linguists use cooperative and collaborative learning interchangeably to refer to similar concept in EFL 
learning and teaching (Nunan, 1992 and Freeman, 2000). However, Oxford (1997) states the slight difference among cooperative, collaborative and interactive learning which are called "communicative strands". Oxford showed their differences as follow:

Cooperative learning refers to a particular set of classroom techniques that foster learners' interdependence as a route to cognitive and social development. Collaborative learning has a "social constructivist" philosophical base, which views learning as construction of knowledge within a social context and which therefore encourages acculturation of individuals into a learning community. Interaction is the broadest of all and refers to personal communication, which is facilitated by an understanding of four elements: language tasks, willingness to communicate, style differences, and group dynamics (Oxford, 1997).

Regardless of such differences, Nunan (1992) and Freeman (2000) often use both cooperation and collaboration interchangeably to refer to instructional use of pair/ small group of students to work together for common benefit. Liang (2002, p.1) states that "the application of cooperative language learning to classroom teaching finds its root in the 1970's when Israel and United State began to design and study cooperative learning models to classroom". The above points indicate that the history of foreign language teaching and learning process has come through various of theories and reaches the current method - cooperative language teaching and learning method which highly assure that we use language to interact with others to foster mutual relationship.

Thus, now a day the new approach to teaching and learning is student centered. Our country's curriculum innovation is highly focused on cooperative learning method which enhances the learners' academic achievements and thereby motivates them to cooperate in problem solving. Salvin (1983) and Dhand (2004, p.50) state cooperative learning is a group of learners organized to learn in which the members of group work cooperate together to find solution to problem. Then, the purposes of cooperative learning are to accomplish the goals or objectives of the group by improving the students' ability to work in group so as to maximize their own and each other's learning.

The above statement confirms that the aim of cooperative language learning is not for individual success, but for common benefit. It also places learning responsibilities on students' shoulders and makes learning more attractive and communicative than the traditional method which gives authority for teachers in solving problem in the class room by themselves. Cooperative learning is the method that provides group rewards based on group members' individual learning consistent to increase students' achievement (Salvin, 1983).

Furthermore, as to Dhand (2004) cooperative learning method is the most powerful way to increase learners' achievement, enhances self-steam, promote positive attitude towards school, develops respect for other student, and facilitates cognitive development so as to increase learners' motivation.
The concept of practice in foreign language learning and teaching is important for utilization of methodologies. Cooperative language learning practice is aimed at activating new linguistic knowledge to be used automatically and correctly in normal communication (Byrne, 1986). For this reason, students are required to engage themselves in extensive production of utterances through active participation. So, practice is what learners have to do from knowing language to using it in real life communication situation and what teachers design, monitor and facilitate to let students practice language cooperatively (Byrne, 1986). Thus, cooperative language learning method takes the primary role to expose students to excessive practice in pair/small groups.

However, the researchers, from their teaching experience has informally noticed that, the place EFL learners give to the right practice of CLL seems not as it is required by its principles. Therefore, the researchers aimed at investigating the practices of cooperative language learning method regarding grade 9 learners of Enango Secondary School located in West Wollega Zone of Oromia Region.

The earliest most widely used method of language teaching and learning was a traditional method or grammar translation method which focuses on teachercentered approach. However, Richards and Rodgers (1998) states that communicative language learning is widely accepted today around the World and it has come to a popular and relatively uncontroversial approach to the organization of classroom teaching. Furthermore cooperative language learning is a part of the more general instructional approach which is also known as collaborative language learning in which maximum use of cooperative activities involving pair and small groups of learners in the class room takes place.

Nunan (1991, p.34) explains that the work of cooperative language learning teams is structured so that there is positive interdependence among the members in the group, the learners feel that they work together for mutual benefit. In well-functioning cooperative group, there is a sense of joint responsibility where learners care about and get committed to each others' success as well as their own; a sense of 'sinking or swimming together.' But Slavin (1983) and Dhand (2004) categorize some learners' instructional preferences in classroom learning process. One is a cooperative incentive structure in which two or more individuals are interdependent for a reward the will share if they are successful as groups. The second is a competitive incentive structure where individuals are rewarded based on their own performances regardless of others performances.

Krashen (as cited in Nunan,1998, pp.167-169) states that learners' learning styles and learning strategies have effect on their cooperative language learning method. It is generally considered that one's learning styles will result from personality variables, including psychological and cognitive make-ups socio-cultural background, and educational experiences.

On the other hand, Petty (1998) and Richards (1998,p.1930) argue that cooperative language learning gives students the experience they need for healthy social, psychological and cognitive development, raises their achievements including those who are gifted or 
academically handicapped. In addition, positive interdependence and individual accountability' are related principles. Learners who work together effectively will find that they need each other to complete the assignments or tasks in classroom; however, if one or more members of the group does not do as much as other members, a common group phenomena will be wastage of time, the group harmony may suffer a serious break down, inhabiting learning and spreading dissent and negative feeling among learners (Matthew, 2004).

Liang (2002) states that CLL approach is not deep rooted and exercised in most parts of the world where English is a foreign language. Although current communicative approach is aimed at developing communicative competence starting from about 1970's, there is less consensus in the field because of some factors. From the factors, few of them are to what extent this communicative skill can easily be attained in actual class room; and whether this objective is attainable in conditions where the target language is not functioning for wider communication purposes (Liang, 2002).

Similarly, the situation of CLL method in our country is not far away from reality. Particularly, among Enango secondary School learners this cooperatives language learning does not seem arrived at its intended objective. A considerable number of students show reluctance while cooperative tasks or assignments are provided and presented in the actual classroom, the practices that most students hold about CLL is very low as the researchers observed informally through their teaching experiences of English as Foreign Language and there is misuse of this learning method from learners' side in effectively applying the right cooperative language learning in EFL classroom. Due to this, the practical utilization of CLL is not this much satisfactory in the school. These could initiate the researchers to conduct a research on this area.

Among researches conducted in Ethiopia related to cooperative language learning, Fedha (2002) and Wondwosen (2008) can be mentioned. Fedha studied the organization of cooperative group work in spoken English II of teachers colleges and his findings labeled that instructors did not properly organize group tasks which were designed, the tasks did not appear to provide the students with helpful learning atmosphere in order to practice speaking.

Wondwosen (2008) also assessed the oral group lessons in English for Ethiopia Grade seven' in promoting cooperative learning and found out that problems of large class size, students poor background knowledge of English, teachers' poor set of a time limit for the discussion and there was little practices of evaluating the oral group lessons offer cooperative learning.

However, the above researchers did not focus on secondary school learners' practices of cooperative language learning. Therefore, the researchers viewed as this area needs further investigation even though there may be other researchers conducted research in this area; to the best of researchers' knowledge, there are limited researches conducted in Ethiopia around CLL method and on factors hindering its practices in EFL class room.
Therefore, this study aimed at investigating the practices of cooperative language learning in the actual classroom of grade 9 in focus. The leading questions to which the research tried to provide answers are the following.

- How is the students active participation in cooperative language learning classroom being carried out?

- What are the factors that impaired the effective practices of cooperative language learning method in EFL classroom?

- What are the activities that can impede CLL method in EFL classroom?

The objective of the study was to investigate the practices of cooperative language learning of learners of English as Foreign language at Enango Secondary School focusing on Grade 9. To achieve the general objective, the following specific objectives have been identified.

This study was aimed to assess the practices of CLL method at Enango High school of Grade 9 in particular. Therefore, it is hoped to have the following significances. EFL teachers get more insights about factors that affect CLL method in EFL classroom and tackle them. It can also raise awareness for the EFL learners' part to be responsible for fostering their CLL method in EFL classroom if they are able to read it from a library since the researchers are willing to provide copy of this research for those who are in need. Still it serves as preliminary information for other interested researchers in the same area to conduct further study. It finally helps as a base of information for supervisors, principals, Woreda Educational offices and other concerned bodies to facilitate learners' active classroom participation so as to improve their CLL.

The study, as mentioned earlier, focuses on investigating the practices of cooperative language learning method of EFL learners at Enango Secondary School-grade 9. It was aimed to assess to what extent learners' actively participate in cooperative language learning during EFL classroom and to explore the hindrances of effective practices of CLL method in EFL classroom. The study area is delimited to one governmental high school, English language learners learning grade 9. The school is found in West Wollega Zone Oromia State of West Ethiopia.

\section{MATERIALS AND METHODS}

The main purpose of the study, as already stated in previous section, is to explore the practices of cooperative language learning of grade nine students. The research design and methodology employed to achieve the objective of the study are treated in this chapter where subjects of the study, sampling techniques, research instruments, data collection procedures, and method of data analysis are described under this section.

\section{The Research Design}

The descriptive research design was used to conduct this study. That is to describe the practices of cooperative language learning in EFL classroom. Descriptive research design was chosen as it allows the researchers to describe the current situation of the subjects of the study. The descriptive research uses systematic procedures to 
discover the relationship between existing variables (Cohen and Manon, 1994).

\section{Subjects of the Study}

The subjects of the study included three English language teachers who teach grade nine at Enango secondary school in 2006 E.C for interview. Besides, students of grade nine in six sections were included in the study for classroom observation and questionnaire.

\section{Sampling Techniques}

In Enango secondary school, there are four English language teachers who teach grade nine. Three of them were selected for the study since one of them became the researcher of this study. These three of the EFL teachers teach six sections of grade nine. They were selected through availability sampling as the researchers assumed that they would provide the best information to address the basic research questions. In availability sampling, the researchers selected all individuals because they would particularly informative about the topic and it may be most informative to interview key personnel, such as principal and teachers who have the experiences (McMillan, 2008). For classroom observation, there were 112 male learners and 189 female students being taught in six sections of grade nine and those six sections were remained to be observed. And also, from 301, about 30 students (10\%) were selected from six sections randomly for questionnaire.

\section{Data Collection Tools}

In order to gather relevant data for the study, the researchers selected three instruments. Close-ended and open-ended items in the questionnaire were translated to Afan Oromo in order to increase its understandability for students; classroom observation and interview questions for EFL teachers were used as data gathering tools in the research. These instruments were developed by the researchers and checked up by other colleagues. They were also given to EFL teachers at Enango Secondary school to check whether the tools were understandable or not, where some amendments were made and used for the intended purposes.

\section{Questionnaire}

Questionnaire is considered to be the most flexible of tools and possesses a unique advantage over others in collecting both qualitative and quantitative research (Singh, 2006). So, the researchers used questionnaire as one instrument for data collection in the current research. Here, the questionnaire consisted of close-ended and open-ended items of which the total number of questions that were used for the practices were 21 close-ended likert scale type and one open-ended that allowed learners to describe explicitly about the practices of CLL. The questions were categorized in to two parts. The first part was provided five scales to show the level of agreement of learners to the principles of CLL method. These were 'strongly agree', 'agree' 'neutral', 'disagree', and 'strongly disagree'. Similarly, some questions were designed to know how often the students practiced CLL by 'always', 'usually', 'sometimes', 'rarely' and 'never'. In general, 30 copies of questionnaires were distributed and all of them were collected by the researchers.

\section{Classroom Observation}

This is the second instrument the researchers preferred to obtain data about the practices of CLL method in EFL classroom while teaching- learning process of English language was being carried out. Here, the researchers used this instrument to triangulate the data gathered through questionnaire and interview. Kothari (1990) and McMillan (2008) state that the information gathered through classroom helps to know what currently takes place, which is not complicated by either the past or future intention or attitudes. Therefore, the researchers aimed to use observation during EFL classroom to assess the practices of CLL; careful arrangements would be crucial in order to identify cooperative based tasks like pair or group activities from learners English text book. The observation was held six times. That was, six sections were observed once based on the teachers' willingness. To do so, checklist focusing on investigating why learners were ineffective in practicing CLL was set and used.

\section{Interview}

Interview was used to gather information that cannot be obtained via observation, as well to verify observational data (Cohen, 1994 and Yalew, 2004. p 177). Its purpose was to explain the participants' point of view, how they interpreted and explained about the given topic. So the researchers made in-depth interviews with a few key participants -EFL teachers currently teaching grade nine students with the assumption that they are particularly knowledgeable and would provide insights and understanding about the problem behind grade ' 9 ' students' practices of CLL.

\section{RESULTS AND DISCUSSION}

In this section, an attempt has been made to express explicitly, the general findings or results of the research were briefly explained.

Of course, the purpose of the research was to investigate how EFL learners effectively practice cooperative language learning method in their actual classrooms. To arrive at the objectives of the study, various data gathering instruments were used. These instruments were close-ended and open-ended questionnaires, classroom observation and in-depth interview. The subjects of the study were three English language teachers for interview, thirty (30) students of grade 9 for questionnaires and 289 students learning in six sections of grade 9 at Enango secondary school in West Wollega Zone for classroom observation. Data gathered from participants were analyzed through both quantitative and qualitative ways. The results gained from the study were summarized in next section. The following table consists of three items that were intended to examine the utilization of cooperative language learning principles which was assumed to be the factor towards CLL in EFL classroom. The grand mean of the responses was computed as 2.5 . 
Table 1: Principles of cooperative language learning

\begin{tabular}{|c|c|c|c|c|c|c|c|c|c|}
\hline \multirow{2}{*}{ No } & \multirow{2}{*}{ Items } & \multicolumn{8}{|c|}{ Responses } \\
\hline & & F \& \% & 5 & 4 & 3 & 2 & 1 & Total & Mean \\
\hline \multirow{2}{*}{1} & \multirow{2}{*}{$\begin{array}{l}\text { I ask my group members and others ask me questions while } \\
\text { we learn in cooperative team in EFL classroom. }\end{array}$} & $\mathrm{F}$ & 2 & 9 & 2 & 17 & -- & 30 & 2.9 \\
\hline & & $\%$ & 6.7 & 30 & 6.7 & 56.7 & -- & 100 & \\
\hline \multirow{2}{*}{2} & \multirow{2}{*}{$\begin{array}{l}\text { I share my role equally with others in cooperative based } \\
\text { tasks }\end{array}$} & $F$ & -- & 3 & 10 & 8 & 9 & 30 & 2.2 \\
\hline & & $\%$ & -- & 10 & 33.3 & 26.7 & 30 & 100 & \\
\hline \multirow{2}{*}{3} & \multirow{2}{*}{$\begin{array}{l}\text { The whole group member participate equally in cooperative } \\
\text { activities. }\end{array}$} & $\mathrm{F}$ & 1 & 2 & 4 & 21 & 2 & 30 & 2.3 \\
\hline & & $\%$ & 3.3 & 6.7 & 13.3 & 70 & 6.7 & 100 & \\
\hline
\end{tabular}

Note: 5 = always $4=$ usually $3=$ sometimes 2 = rarely 1 = never; $F=$ frequency and $\%$ percentage.

As the above table indicated the responses for item 1 regarding the existence of interaction among learners, 2 $(6.7 \%)$ of the respondents showed that they "always" ask and answer questions with their teammates. And 9(30\%) replied that they "usually" interact with one another while 2 $(6.7 \%)$ and 17 (56.7) of the learners responded that they "sometimes" and "rarely" respectively. The mean value was computed as 2.9 which indicated that there was nearly sometimes asking and answering among learners. The information obtained from classroom observation and teachers' interview also depicted that there was no firm interaction among learners because of lack of language proficiency, inability to express their opinion (lack of speaking skills using EFL), fear of making mistakes, lack of interest or unwilling to work together and shyness which are some among the problems that hinder them from effective interaction in EFL classroom.

Item 2 was intended to elicit responses if each team members share their roles which they have or assigned with in a group, and $3(10 \%)$ of the learners "usually" share the role they had, $10(33.3 \%)$ of them "sometimes" play their role 8 (26.7) "rarely" and $9(30 \%)$ of the respondents share their role. The total mean of these responses was 2.2 that showed learners rarely played the roles that they were provided with in a group. As of the data gained through classroom observation, the researchers tried to observe while learners were instructed to do the given tasks in their cooperative groups; however, no students was observed playing their roles equally seen in the group as reporters', turn takers etc.

Coming to item 3 , it was aimed to assess how the learners in cooperative group participate in the same way with one another in CLL. A single person $(3.3 \%)$ of the learners "always" participate equally with teammates $2(67 \%)$ of them "usually" while $4(13.3 \%)$ "sometimes". However, 21, (70 \%) and $2(6.7 \%)$ of the learners participate "rarely" and "never" respectively in the given cooperative activities. It was possible to conclude from the above result that was shown by mean value 2.3 that learners rarely participate in the given cooperative learning equally with each others. The results from classroom observation and interview also indicated that only the group leader tried to deal with the activities.

\section{Utilization of Communicative Activities}

The items in the following table were designed to examine how often the communicative activities are used and how often those shy and slow learners are encouraged by top learners to actively involve in cooperative tasks during EFL classroom.

Table 2: Provision of pair/group activities

\begin{tabular}{|c|c|c|c|c|c|c|c|c|c|}
\hline \multirow{2}{*}{ No } & \multirow{2}{*}{ Items } & \multicolumn{8}{|c|}{ Responses } \\
\hline & & F \& \% & 5 & 4 & 3 & 2 & 1 & Total & Mean \\
\hline \multirow{2}{*}{1} & \multirow{2}{*}{$\begin{array}{l}\text { Communicative activities or pair/group works are } \\
\text { given in EFL classroom }\end{array}$} & $f$ & 5 & 7 & 18 & --- & --- & 30 & 3.6 \\
\hline & & $\%$ & 16.7 & 23.3 & 60 & --- & --- & 100 & \\
\hline \multirow{2}{*}{2} & \multirow{2}{*}{$\begin{array}{l}\text { Those of shy and slow learners are motivated or } \\
\text { encouraged by their teammates }\end{array}$} & $f$ & 1 & 4 & 6 & 13 & 6 & 30 & 2.4 \\
\hline & & $\%$ & 3.3 & 13.3 & 20 & 43.3 & 20 & 100 & \\
\hline
\end{tabular}

Item 1 was intended to investigate how often the communicative activities and group/pair work are provided in EFL classroom. Five (16.7\%) of the learners reported that those activities were given "always" and $7(23.3 \%)$ replied that they were "usually" given while $18(60 \%)$ of the respondents displayed that communicative activities are "sometimes" practiced. The mean value was computed as 3.6 which lied between "usually" and "sometimes".

Item 2 was focused on whether shy and slow learners were motivated or encouraged by other team members in order to actively take part in cooperative group activities. Therefore, $3.3 \%$ of the learners replied that they were "always" encouraged, 4 (13.3\%) of the respondents said were "usually" and about 6(20) reported that they were "sometimes" motivated, however $13(43.3 \%)$ and 6(20\%) of them were encourage "rarely" and "never" respectively. Its mean value was calculated to 2.4 that indicated as the responses inclined to be "rarely". This was to mean that some of shy and slow learners that might be within a group were not frequently encouraged in order to improve their cooperative skills to actively participate together with other who are actively involved in CLL. As far as the results gained through classroom observation was concerned, there were a considerable number of learners who were frustrated, afraid and felt shy, and unable to express their ideas. And there were some learners who were observed or seen while they were smiling or laughing at those who tried to say something. So, these kinds of situations revealed among learners and could be the factors that were assumed to affect the practices of cooperative language learning in EFL classroom.

\section{Learners' Discussion and Sharing Experiences in EFL Classroom}

The following table incorporates three items that focused on whether the learners discuss, teach and share their experiences with one another whenever they learn cooperatively in EFL classroom. 
Table 3: Learners' discussion and sharing of experiences

\begin{tabular}{|c|c|c|c|c|c|c|c|c|c|}
\hline \multirow{2}{*}{ No } & \multirow{2}{*}{ Items } & \multicolumn{8}{|c|}{ Responses } \\
\hline & & F \& \% & 5 & 4 & 3 & 2 & 1 & Total & Mean \\
\hline \multirow{2}{*}{1} & \multirow{2}{*}{$\begin{array}{l}\text { I explain, discuss and teach what I } \\
\text { understand to other group members. }\end{array}$} & $f$ & 2 & 9 & 2 & 17 & --- & 30 & 2.9 \\
\hline & & $\%$ & 6.7 & 30 & 6.7 & 56.7 & --- & 100 & \\
\hline \multirow{2}{*}{2} & \multirow{2}{*}{$\begin{array}{l}\text { Group leaders facilitate and manage the } \\
\text { rest of members. }\end{array}$} & $f$ & 9 & 15 & 4 & 2 & --- & 30 & 4.3 \\
\hline & & $\%$ & 30 & 50 & 13.3 & 6.7 & --- & 100 & \\
\hline & \multirow{2}{*}{$\begin{array}{l}\text { Those of high achievers share their } \\
\text { experiences to other learners. }\end{array}$} & $f$ & 7 & 3 & 10 & 10 & --- & 30 & 3.2 \\
\hline & & $\%$ & 23.3 & 10 & 33.3 & 33.3 & --- & 100 & \\
\hline
\end{tabular}

Item 1 was intended to obtain data on how often learners explain, discuss or teach what they understand to teammates while learning or doing different activities cooperatively in EFL classroom.

From the participants $2(6.7 \%)$ of them reported that they "always" explain or teach the other members, $9(30 \%)$ of the respondents responded "usually" and 2(6.7\%) "sometimes" helped or supported one another, nevertheless $2(6.7)$ and $17(56.7 \%)$ of them "rarely" and "never" explain and discuss their understandings in the sense of giving assistance for others. When the mean value of the responses computed it was 2.9 which was within the range of between sometimes and rarely.

From the above points forwarded for item 1, it could be possible to say that there was not so much of helping or supporting each other so as to increase the involvement of CLL during EFL class room.

Coming to item 2 , in table 3 , it was designed to investigate if the group leader in cooperative learning facilitates or manages the rest of members. Here, $9(30 \%)$ of the learners reported that they "always" facilitate, and $15(50 \%)$ of the respondents replied that they "usually" manage the group members while $4(13.3 \%)$ of them replied "sometimes", however $2(6.7 \%)$ of the respondents said "rarely". The mean value of the responses was computed 4.3 which indicated that the group leaders assigned usually facilitate and manage the other members during the cooperative based task are provided in EFL classroom though each group members have their own roles.
Item 3 was intended to assess if high achievers share their experiences for other learners. Those $7(23.3 \%)$ of the learners share their experience "always" and $3(10 \%)$ of them share "usually" while 10 (33.3\%) 10 (33.3\%) share "sometimes" and "rarely" respectively. The total mean was computed 3.2 this was almost "sometimes".

From the above points, it was possible to conclude that there was 'sometimes' sharing of experiences among learners of EFL.

Concerning the items in the above table, Richards and Rodgers (1998) and Jacobs (1988) stated that positive interdependence refers to group members that need each other in order to complete the groups' tasks with the feeling if single for all and all for one or sink or swim together. And also in CLL, learners are responsible and encouraged to explain ideas or skills to one another, each of them being active participant, slower learners will benefit from peer tutoring by teammates (Nunan 1992, p.36). Therefore, when we sum up the result from the table, there were problems of sharing the roles they were provided in a group, unequal participation and unable to motivate and encourage those of shy and slow learners were somewhat vividly seen.

\section{Students' Organization in Cooperative Groups}

Cooperative language learning method was deliberately ad heterogeneous used by EFL teachers after careful consideration and consisted of two to four members which were high, average and low achievers (Nunan, 1992, p.36). Accordingly, the students were asked different questions to get data about the extent to which they practice CLL during EFL class room.

Table 4: Organization of cooperative groups

\begin{tabular}{llrrrrrrrc}
\hline No & \multicolumn{1}{c}{ Items } & $\mathbf{F ~ \& ~ \% ~}$ & $\mathbf{5}$ & $\mathbf{4}$ & $\mathbf{3}$ & $\mathbf{2}$ & $\mathbf{1}$ & Total & Mean \\
\hline \multirow{2}{*}{1} & There high, medium and slow learners in cooperative & $\mathrm{F}$ & 21 & 7 & --- & 2 & --- & 30 & 4.5 \\
\cline { 2 - 10 } & group of the school. & $\%$ & 70 & 23.3 & --- & 6.7 & --- & 100 & \\
\hline
\end{tabular}

$\mathrm{N} . \mathrm{B} \mathrm{F}=$ frequency $\%=$ percentage

As could be observed from the above table, item 1 dealt with the organization of cooperative group in EFL learning classroom. So, about $21(70 \%)$ and $7(23.3 \%)$ of the respondents replied that they "strongly agree" and "agree" respectively. It shows that organization of cooperative group was grouped with mixed ability. And only $2(6.7 \%)$ of the participants were "disagreed" with the given item. When this was described in terms of mean, the mean value of the respondents for the first item was 4.5 which was on the point of strongly agree with regard to the scale. As to the information gained through interview with three EFL teachers, similar ideas were forwarded that the cooperative groups in classroom are organized with mixed abilities like high, medium and slow learners since this method is required by MOE.
Since the responses from the students' questionnaires were based on the organization of cooperative group, it was found out that the greater number of students with the mean value of 4.5 depicted that the cooperative arrangements during EFL classroom were grouped based on the way to promote the cooperative language learning. However, only a few of the respondents showed their disagreement that there was no heterogeneity grouping with less mean value. The data gathered through classroom observation and teachers' interview highly confirmed that there were the consideration of learners' abilities in grouping the cooperatives team while learning EFL, i.e there was the mixture of high, medium and slow achievers in every cooperative activities. 
In response to learners' understanding of the importance of cooperative language learning, almost all of them were found to have well understanding with mean score of 4.0 which indicated that the CLL method was widely understood with its greater advantage among learners. This also revealed similar result with the response gathered from EFL teachers' interviews.

Regarding learners' concepts of working together in cooperative group in the way to complete the group's tasks for mutual benefits, the majority of the students with cumulative mean score of 4.4 claimed that cooperative language learning fosters their social skills and enables them to benefit mutually. Only $10 \%$ of the respondents reflected their disagreement on the above point. As much as the classroom resources like table arrangement and class environment was concerned, a considerable number of learner respondents strongly disagreed on the availability of classroom environment and sitting arrangement to perform cooperative activities. This point was raised in other sources as there is a great problem of classroom situation for the large number of learners in each class made the cooperative activities unmanageable, impossible to identify who performed and who did not perform the given cooperatives tasks in group members.

As it could be witnessed from the responses of providing equal rewards or motivation for each cooperative group members for any contribution made during EFL classroom, almost all with the mean score of 2.2 portrayed that equal motivation or rewards were not provided for each group members. This could be the reason why EFL teachers were mostly hurried to complete or summarize the given topic of the day. And also there were learners who wanted to give responses remained unlucky to express their ideas as observed during the classroom observation, which led them to unequal gift or rewards in the EFL classroom.

\section{Learners' Concepts of CLL}

The following table incorporates three items reflecting the understandings of students about the concept of CLL. More than the average number of the studentrespondents with the grand mean value of 4.2 showed their agreement about the concept of CLL.

Table 5: Students' understanding of CLL

\begin{tabular}{|c|c|c|c|c|c|c|c|c|c|}
\hline \multirow{2}{*}{ No } & \multirow{2}{*}{ Items } & \multicolumn{8}{|c|}{ Responses } \\
\hline & & f \& \% & 5 & 4 & 3 & 2 & 1 & Total & Mean \\
\hline \multirow{2}{*}{1} & \multirow{2}{*}{$\begin{array}{l}\text { Cooperative learning is more } \\
\text { advantageous than working alone }\end{array}$} & $F$ & 8 & 17 & 2 & 3 & --- & 30 & 4 \\
\hline & & $\%$ & 26.7 & 56.7 & 6.7 & 10 & --- & 100 & \\
\hline \multirow[b]{2}{*}{2} & \multirow{2}{*}{$\begin{array}{l}\text { We gain the concept of leadership, } \\
\text { problem solving and interpersonal } \\
\text { skill from CLL }\end{array}$} & $\mathrm{F}$ & 16 & 9 & --- & 5 & --- & 30 & 4.2 \\
\hline & & $\%$ & 53.3 & 30 & --- & 16.7 & --- & 100 & \\
\hline \multirow{2}{*}{3} & \multirow{2}{*}{$\begin{array}{l}\text { Working in cooperative group } \\
\text { enables to complete groups, tasks } \\
\text { for mutual benefits }\end{array}$} & $\mathrm{F}$ & 15 & 12 & 3 & --- & --- & 30 & 4.4 \\
\hline & & $\%$ & 50 & 40 & 10 & --- & --- & 100 & \\
\hline
\end{tabular}

The first item in table 5 was about the importance of cooperative learning comparing with the individual learner in order to check their understanding about the advantages of CLL. Concerning this point Richards and Rodgers (1998) stated that CLL raises the achievement of all students including those who are gifted or those who are academically handicapped, gives students the experiences they need for healthy social, psychological and cognitive development. Therefore, in response to this item, 8 (26.7) respondents "strongly agreed" and 17 $(56.7 \%)$ of the student-participants reported that they "agreed" with the item. 2(6.6) of them were unable to decide and finally $3(10 \%)$ of them showed their "disagreement". As far as the result obtained from teacher interview was concerned, three of the interviewees responded similar responses. To sum up, respondents with the mean score of 4.0 have the understanding of the advantages of CLL.

Regarding item 2, the question was focused on if the learners have the concept of working or learning in cooperative group's tasks for mutual benefit. For this, 15 $(50 \%)$ of the respondent were "strongly agreed", $12(40 \%)$ of them agreed that cooperative language learning enhances working together for mutual benefit. However, 3 $(10 \%)$ were unable to decide. When its mean was computed, it was about 4.4 which indicated that the majority of the participants were "agreed" with it. As far as the results from teachers' interview were concerned, two of the interviewees confirmed that the students know the importance of cooperative language learning. Only one interviewee had a contradictory idea that not all students have understanding of CLL. So, it was possible to conclude that the majority of the learners in Enango Secondary school have understood the benefits of cooperative language learning.

\section{Conduciveness of the Classroom Environment}

The following item focused on whether the classroom environment was conducive for the promotion of cooperative language learning during EFL classroom or not.

Table 6: Classroom environment

\begin{tabular}{|c|c|c|c|c|c|c|c|c|c|}
\hline \multirow{2}{*}{ No } & \multirow{2}{*}{ Items } & \multicolumn{8}{|c|}{ Responses } \\
\hline & & f \& \% & 5 & 4 & 3 & 2 & 1 & Total & Mean \\
\hline \multirow{2}{*}{1} & \multirow{2}{*}{$\begin{array}{l}\text { The resources like arrangement of tables and } \\
\text { classroom environment are available for CLL }\end{array}$} & $f$ & 2 & 3 & -- & 8 & 17 & 30 & 1.8 \\
\hline & & $\%$ & 6.7 & 10 & -- & 26.7 & 56.7 & 100 & \\
\hline
\end{tabular}

When coming to item in table $6,2(6.7 \%)$ of the learners "strongly agreed" and $3(10 \%)$ of them showed their "agreement". Nevertheless, about 8 (26.7\%) were "disagreed" and $17(56.7 \%)$ displayed their ideas with the 
mean value of 1.8 which indicated that there were the problems of resources like the arrangement of table and classroom environment that extremely hinder practices of CLL during EFL classroom. Dhand (2004) confirmed that the cooperative learning is not having students sit side by side.

The result from the classroom observation also revealed that the learners were not smoothly participating in the given cooperative tasks. When the teacher assigned them to discuss on the topic the students were distressed and troubled to move round to one another- the chair was not movable and the number of students were also not standardized. Littlewood (1995) stated in CLL a number of factors like remembering the point made in connection with classroom interaction and the situation must be capable of stimulating learners to high degree of communication involvement. The results from the interview can also be evidence that all interviewees expressed under one general question as the greatest problem towards CLL method are a large class size, the resources in the classroom, the class furniture like tables are not available. Likewise, the researcher tried to observe six sections while similar problems were appeared in EFL classroom.

\section{Whether Equal Rewards or Motivation are Provided for Students or Not}

This table was intended to explore if learners were provided equal rewards or motivation for any contribution they made whenever cooperative activities were given during EFL classroom.

Table 7: Learners' motivation or rewards in EFL classroom

\begin{tabular}{|c|c|c|c|c|c|c|c|c|c|}
\hline \multirow{2}{*}{ No } & \multirow[b]{2}{*}{ Items } & \multicolumn{8}{|c|}{ Responses } \\
\hline & & f \& \% & 5 & 4 & 3 & 2 & 1 & Total & Mean \\
\hline \multirow{2}{*}{1} & \multirow{2}{*}{$\begin{array}{l}\text { Each team members gets equal rewards or } \\
\text { motivation for any contribution they made. }\end{array}$} & $f$ & 2 & 3 & 2 & 14 & 9 & 30 & 2.2 \\
\hline & & $\%$ & 6.7 & 10 & 6.7 & 46.7 & 30 & 100 & \\
\hline
\end{tabular}

Item in table 7 , that was intended to elicit information whether each cooperative team members gets equal rewards or motivation for any contribution they made as a group during EFL classroom. The students' responses depicted that $2(6.7 \%)$ of them "Strongly agree" and 3 $(10 \%)$ of them "agreed", $2(6.7 \%)$ were remained "neutral". On the other hand, $14(46.7 \%)$ "disagreed" while $9(30 \%)$ "Strongly disagreed". The mean value of the responses computed as 2.2 which showed that the majority of the respondents disagreed that there was no equal rewards given for all group members.

As far as the result from classroom observation was concerned, the researchers observed about six sections while cooperative based tasks were being taught. From those sections, almost all of them were not given equal rewards. For instance, some teachers were hurried to give corrections even before the other groups completed the tasks provided. Even though the teachers tried to give rewards for each of the students orally, there were a number of students who could not get chances to give their responses. That was why most of them remained unlucky to get equal rewards from their teachers. As far as the result gained from interview was concerned, absence of giving equal rewards could be because of the large number of students assigned in each classroom that was difficult to manage, to give feedback for students, to facilitate the program. Thus, lack of equal rewards could lead the learners to delay in practice of working cooperatively. To this point, Slavin (1983) and Shamim et al. (2001, p.36) confirmed that cooperative learning is the method that provides group rewards based on group members' individual accountability and learning consistently that increases their achievement. Also it is in which all group members have equal access and maintain joint rewards by setting criteria in which all group members are rewarded, and assigned roles for group members (Jacobs, 1988).

In the next section, the responses based on learners' ability or confidence of speaking skill while learning English cooperatively obtained from different sources and tools, students responded that they lack competence in speaking using English, unable to talk fluently with their partners during discussion in EFL classroom were dealt with. And learners lack of vocabularies, their shyness, afraid of one another and loses of linguistic competence were referred to. The result from the classroom observation also indicated as only those of high achievers tried to speak while the majority of the students felt shy and frustrated when they were asked to forward what they discussed in their groups.

Proceeding to the responses about learners role in cooperative group members, the learners in cooperatives group during EFL classroom generally have their own role as a member, like group leader, secretary and so on which was assigned by their subject teachers or homeroom teacher. However, as the responses obtained from different sources, there was absence of playing roles that they have in cooperative group. The results from class room observation could be used as evidence that learners were unable to share their roles as group members equally. Some learners who were assigned as group leaders seemed as they played their roles by trying to respond in any activities provided. In addition, only those of high achievers took the burden of performing the tasks given in a group, even the other slow or medium learners might not know what was being accomplished as responses from interview questions confirmed.

As the responses on designing the cooperatives activities using different techniques in the way to help learners to participate actively in cooperative languages learning, less than average number of learners with mean values of 2.5 agreed as various techniques and different designing of cooperative activities were practiced in EFL classroom. While a considerable number or more than average number of students revealed that there was no firm utilization of different cooperative techniques and designing or facilitating on the behave of making participatory activities in EFL learning classroom.

Moreover, the learners' classroom interaction was displayed by less than average number of students that there was good interaction among cooperative group members. But the majority of the respondents showed that earners were incapable of interacting in the 
classroom. They did not ask and answer questions in their groups or usually they were afraid of talking with one another in the classroom. Although communicative activities were given every time, there was lack of interaction observed for the reason of learners' shyness and fear of sharing their view or unwillingness to expose themselves to cooperative group members. Also there was lack of motivation and encouragement for those of shy and afraid learners from the other teammates.

However, those of high achievers tried to facilitate and manage the group members during class activities, and as responses from participants of questionnaire, the high achievers had the sense of sharing their experiences to other teammates in order to support or help each other. The responses from open-ended questionnaire depicted that there was lack of interest to work together among some learners, unwillingness of a few students to be members of their own groups assigned by their subject teachers, lack of enough time provided to accomplish the cooperative activities in the classroom, and difficulty of fairly distributing learners in each cooperative group based on the ability (ineffective forming of heterogeneous groups) were among the problems mentioned.

Furthermore, the responses on the difficulty of learners to practice CLL, EFL teachers explained that family educational background has a great contribution on learners' activities in CLL. If the learners were encouraged or motivated to share their point of view and had freedom to speak in their families, they also could actively participate when they engage in school and have confidence to work cooperatively with their team mates. Finally, the number of students allocated in each classroom was not standardized as the requirement of the Ministry of Education.

\section{CONCLUSIONS}

The overall findings of the research indicated that the organization of cooperative groups in EFL classroom is mostly by considering the knowledge learners to form heterogeneous group and each cooperative team members has their own role assigned by their subject teachers. However, the heterogeneity of the cooperative group was not strictly done by carefully considering the skills of learners. Even though each individual members of the group has their own roles, the problems revealed were the shortage of sharing the roles equally with teammates or lack of equal participation with cooperative group. The burden of the given cooperative activities assignments and project works are mostly on the high achievers assigned as group leaders. So, the cooperative activities were inclined to be individualized. Thus, cooperative skill cannot be gained if only one or two members are in charge of the tasks.

Cooperative language learning is interconnected with learner's classroom interactions while learning in EFL class room; however there was no hot interaction seen among EFL learners. This was because of the feeling shyness, lack of language proficiency or lack of words to speak in English. And also there was lack of interest to work cooperatively among some students. So, there were learners who were unwilling to expose themselves in their team members for fear of making mistakes. For these problems, family educational background has a great contribution on learner's cooperative activities participation. The family in which the learners have grown up has roles in motivating or encouraging them to cooperate with others.

There was also not different cooperative techniques designed which were strictly used to promote cooperative language learning and the designing or facilitating the cooperative tasks in the way to help the learner's to participate actively was not widely observed. What was usually tried to be performed was already as it is on the text book. But in cooperative language learning, the attention should be paid to structure the task so as to insure learners working together interdependently and accountably. And finally the resources in the classroom, the sitting arrangement or learners' chair were not suitable for CLL. And the number of students in each classroom were unmanageable and difficult to involve in cooperative activities and to follow the participation of student, to give feedback equally at the same time during EFL classroom and to monitor how well the cooperative groups are working together.

\section{Conflict of Interest}

Authors declared no conflict of interest.

\section{Acknowledgements}

First and foremost, the authors would like to thank all the staffs of Enango Secondary School and the students who provided us the necessary data to conduct this study. Our sincere gratitude also goes to the Department of Language Studies and Literature at Wollega University to help us by following up to the end.

\section{REFERENCES}

Apple, M.T. (2006). Language learning theories and cooperative learning techniques in EFL Classroom. Doshish Studies in Language and culture 9(2): 277-300.

Befekedu Zeleke and Hussien Kadir (2009/10). Research Design and Methodology in Education. Addis Ababa University, Addis Ababa, Ethiopia.

Brown, H.D. (1994). Teaching by principle: An Interactive approach to language teaching pedagogy $\left(2^{\text {nd }}\right.$ ed.). New Jersey: Prentice Hall. Reagents.

Brown, H.D. (2000). Principles of Language Learning and Teaching $\left(4^{\text {th }}\right.$ ed.).New York: Addison Wesley Longman, Inc.

Byrne, D. (1986). Teaching oral English $\left(2^{\text {nd }} e d\right)$.London: Longman publishing.

Cohen, L. and Manon, L. (1994).Research Methods in Education ( $4^{\text {th }}$ ed.). New York: Rutledge.

Farron, J.S. (1981). Principles and Practices of Education. Longman.

FedaNegesa (2002). The Organization of Group Work In Spoken English II Classes. Addis Ababa University, Addis Ababa, Ethiopia.

Freeman, L. D. (1986). Techniques in Language Teaching. Cambridge: CUP

Ghand, H. (2004). Technique of Teaching. A shish publishing House: New Delhi.

Harmer, J. (2001).The practice of English Language teaching $\left(3^{\text {rd }} \mathrm{ed}\right)$. Longman: Pearson Education Ltd.

Jacobs, G. (1988). Cooperative goal structure: A way to improve group activities. ELT Journal 42(2): 97-101. 
Zeleke Teshome Lucha \& Tsega Megersa Bongase

Johnson, D.W. and Johnson R. T. (1990). Social skills for successful group work. Educational Leadership 47(2): 2933.

Kagan, S. (1994). Cooperative learning. California: Kagan Publishing.

Kessler, C. (1992). Cooperative language learning: A teacher's resource book. Prentice Hall.

Kothari, C. R. (1990). Research Methodology. Methods and Techniques (2nded). New Age International Publisher.

Liang, T. (2002). Implementing Cooperative Learning In EFL Teaching. Process and Effects. National Taiwan Normal University.

Little wood, W. (1995). Communicative Language Teaching. Cambridge Language Teaching Library: CUP.

Mathew, T. A. (2004). Language Learning Theories and Cooperative Learning Technique in EFL Class room. Ritsumeikan University, College of Letters.

McMillan, J.H (2008). Education Research. Fundamentals for the Consumer-Boston: Pearson.

Nunan, D. (1991). Language Teaching Methodology. Text book for Teachers. Prince Hall International : UK.

Nunan, D. (1992). Collaborative Language Learning and Teaching. Cambridge: CUP

Oxford, R. L. (1997). Cooperative Learning, Collaborative Learning, and Interaction: Three Communicative strands
Sci. Technol. Arts Res. J., April-June 2015, 4(2): 278-287 in language classroom. The modern Language Journal, 81(4): 443-445.

Petty, G. (1998). Teaching Today. A Practical Guide . $\left(2^{\text {nd }} e d\right)$. Stanley Thrones. UK.

Richards. J. and Rodgers, S.T. (1998). Approaches and Methods in Language Teaching $\left(2^{\text {nd }} e d\right)$. University of Hawai.

Salvin, E.R. (1983). When does Cooperative Learning Increase Students Achievement? Psychological Bulletin 94.

Slavin, R.E. (1990). Cooperative Learning. New Jersey: Prince Hall.

Shamim, F., Negash, N., Chuku, C. and Demewoz, N. (2007). Maximizing Learning in Large Classes: Issues and Options. Addis Abbaba: The British Council. http://www.teachingenglish.org.uk/sites/teacheng/files/EL T-16-screen.pdf

Ur, P. (1996). A Course in Language Teaching. Practice and Theory. Cambridge: CUP.

Wondwosan T/Michael (2008). Assessment of the Oral Group Lesson in 'English for Ethiopia. Grade Seven. In: Promoting CL. AAU.

Yahya, N. (n.d). Reaching English Language Learners through Cooperative Learning. Florida Atlantic University. USA 